\title{
CO-COMBUSTION OF BIOMASS IN A COAL-FIRED POWER PLANT UNIT
}

\author{
Yoshihiro IDETA *, Yohei HADA**, Akito MUROI** and Atsuya DEGUCHI* \\ *Construction Group Fossil Power Division, The Kansai Electric Power Co., Inc., \\ 3-6-16 Nakanoshima, Kita-Ku, Osaka 530-8270, Japan \\ **Engineering Center Fossil Power Division, The Kansai Electric Power Co., Inc., \\ 3-2-18 Nakanoshima, Kita-Ku, Osaka 530-0005, Japan
}

\begin{abstract}
In expectation of mixing wood pellets in the fuel at Maizuru Power Plant Unit 1 ("Plant) at the Kansai Electric Power Co., Inc., we have been conducting tests using in-house testing equipment to determine pulverization and combustion characteristics of the wood pellets. As a result, the pellets' characteristics were successfully ascertained. In line with the upcoming commencement of mixed fuel operation, we have implemented trial runs at the Plant in an effort to establish a method for setting the maximum mixing ratio in a coal pulverizer with different coal properties, and to confirm the combustion characteristics and boiler heat absorption balance.
\end{abstract}

Keywords: Biomass, Wood Pellet, Pulverization, Combustion

\section{INTRODUCTION}

In recent years, the scope of biomass energy use has been expanding as a measure to prevent global warming. Biomass is defined as "biological material derived from organisms, excluding fossil resources." The energy derived from biomass is referred to as "biomass energy". Biomass is considered carbon neutral because it releases carbon dioxide (a gas which causes global warming) absorbed in the process of their growth, and thus does not increase carbon dioxide in the atmosphere when it's burned. The Kansai Electric Power Co., Inc, has been taking steps toward mixing wood pellets in the fuel in an effort to reduce carbon dioxide emissions from coal-fired power plant. Wood pellets are made of such materials as sawdust and shavings (i.e., biomass materials) pulverized, dried, and compacted into a cylindrical form.

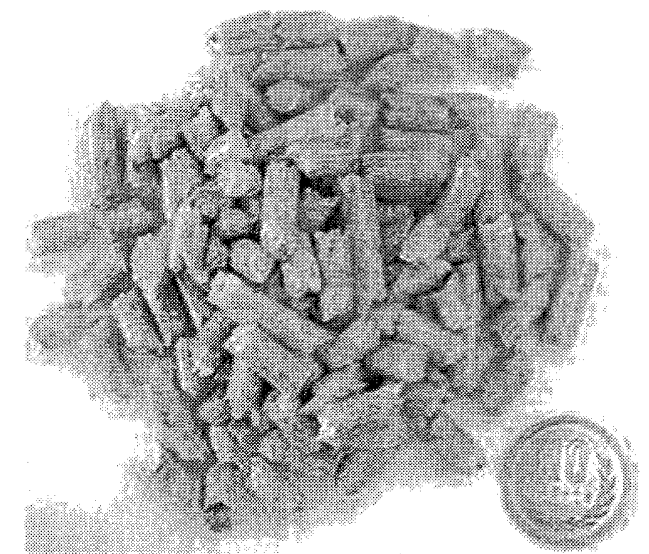

Fig. 1 Wood Pellets (a photograph)

Prior to mixing wood pellets in the fuel, we investigated transportation/storage characteristics, ease of pulverization, and properties of exhaust gas/fly ash generated in combustion. Based on the investigation results, we developed a business scheme including the volume of pellets to be mixed in the fuel and procurement procedure, etc. In the initial phase of using wood pellets at the Plant, we established operational indices for the equipment (including conveyors and a coal pulverizer) through repeated trial runs and evaluations. This report is intended to present the results of pulverization and combustion tests conducted to calculate the maximum ratio of wood pellets mixed with coal (primary fuel).

\section{PULVERIZATION TEST}

\subsection{Experimental}

Coal, which is fed from the coal feed pipe at the top of the coal pulverizer, falls onto a turning pulverization table, and is pulverized by a roller. Pulverized coal rises upward while being dried by air which is fed from the periphery of the pulverization table. Pulverized coal is screened to a specified particle size by a flow deflector and a rotary separator before it is fed into a boiler. Fig. 2 shows the schematic drawing of the coal pulverizer used at the Plant. At the Plant, the equipment is designed to handle. For example, the coal pulverizer is designed to generate the rated output even when pulverizing even some brands of coal which are difficult to pulverize and thus require higher power consumption. Therefore, we can afford a power consumption in coal pulverization except for the coal which lead the standard indices of the Plant. On the other hand, since biomass contains fibrous materials, power consumption required by the coal pulverizer is high for wood biomass. Indeed, pulverization efficiency of wood pellets is lower than that of coal. For this reason, the volume of wood pellets to be mixed with coal needs to be estimated based on the available capacity of the coal pulverizer (in terms of power consumption) which differs for each brands of coal. However, well-defined indices had not been developed for pulverization characteristics of

\footnotetext{
Copyright $(2009$ by the Japan Society of Mechanical Engineering
} 
wood pellets in the coal pulverizer. Thus, we conducted pulverization tests on three different brands of coal with wood pellets mixed, and examined the technique to simply estimate the volume of wood pellets which can be pulverized with the available capacity of the coal pulverizer (in terms of power consumption). In the pulverization tests, we adjusted the surface pressure of the coal pulverizer roller, the table's rotational speed, and the rotary separator's rotational speed, and evaluated the coal pulverizer's power consumption, the table's differential pressure, and fineness of pulverized fuel. The table's differential pressure can be obtained by measuring the pressure of primary air at before and after passing through the pulverizing table. This is one of the major conditions to show the status of the coal pulverizer. When pulverization is not smooth, the circulation volume of pulverized fuel grows in the coal pulverizer, which leads to an increase in table's differential pressure. In the mixed pulverization tests at this Plant, we used only one coal pulverizer out of six to minimize the impact on the unit's operation. We selected the coal pulverizer with the lowest pulverization capacity based on the condition of roller's abrasions to prevent overestimation of the coal pulverizer's performance.

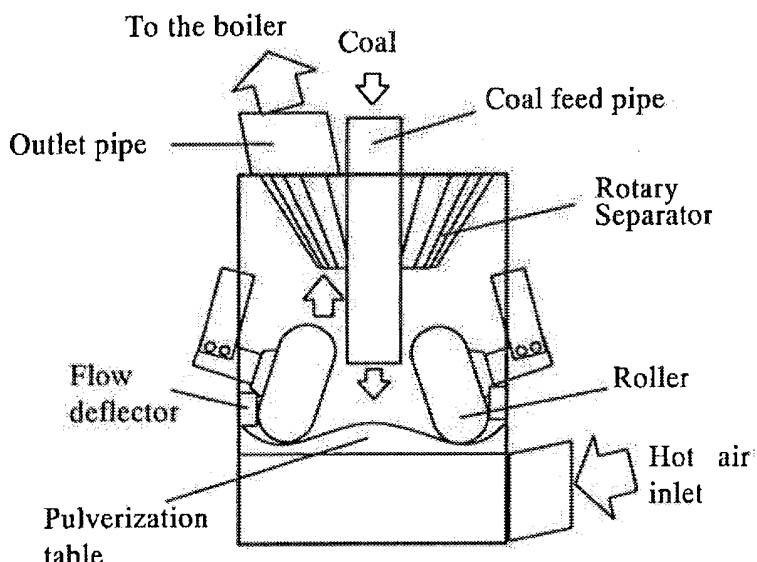

Fig. 2 Schematic Drawing of the Vertical Coal Pulverizer

\subsection{Result and Discussion}

Fig. 3 shows the coal pulverizer's power consumption depending on the ratio of wood pellets mixed with coal. The coal pulverizer's power consumption increases almost linearly in direct proportion to the mixing ratio for all the brands of coal. The inclination of the graph was almost the same for all the brands of coal.

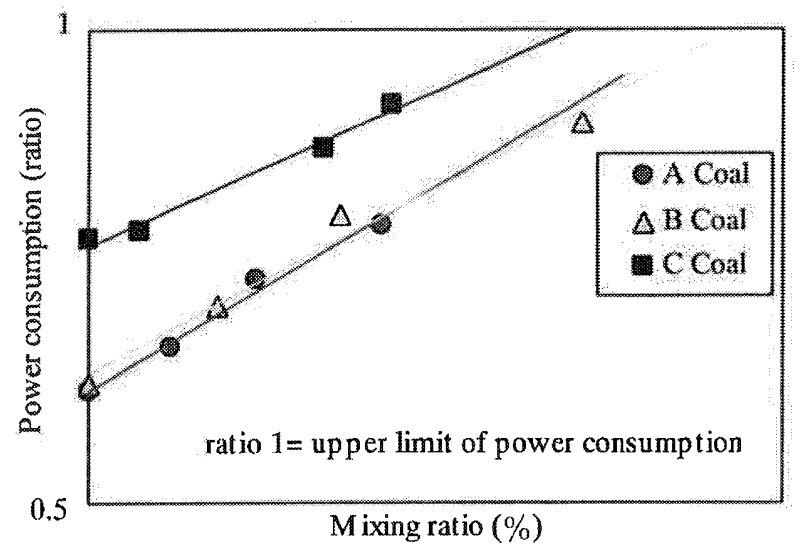

Fig. 3 Power Consumption Required by the Coal Pulverizer
Fig. 4 shows the table's differential pressure against mixing ratio of wood pellets. For all the brands of coal, the table's differential pressure did not show a significant increase associated with mixing of wood pellets. This is attributed to the rotary separator in the coal pulverizer which kept the table's differential pressure constant. We confirmed that the table's differential pressure does not exceed the limit value when wood pellets are mixed, as long as the coal pulverizer's power consumption does not exceed the upper limit. Thanks to automatic control of the rotary separator, the table's differential pressure did not show a significant increase, but power consumption for pulverization grew linearly with the increase of the mixing ratio. It is reasonable to believe that mixing of wood pellets affects the coal pulverizer's performance, and that particle size of pulverized products change. Thus, we decided to check the particle diameter after pulverization.

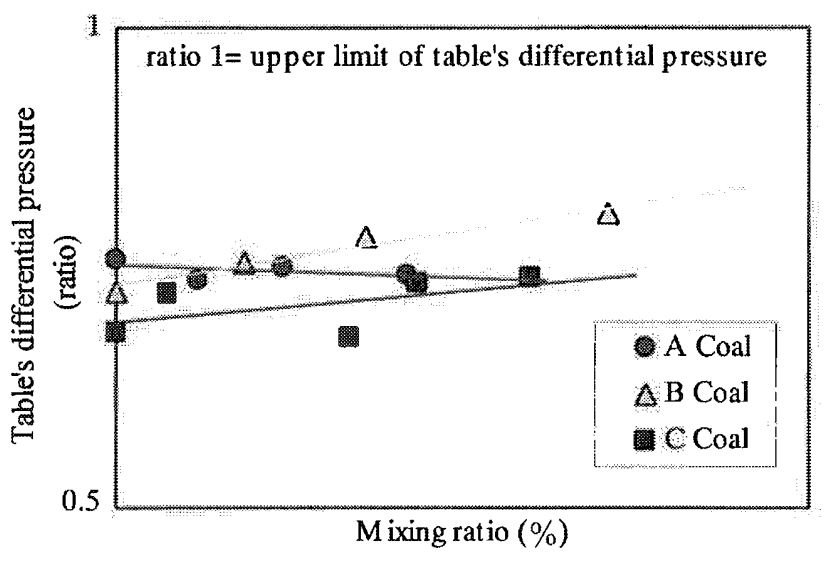

Fig. 4 Table's Differential Pressure
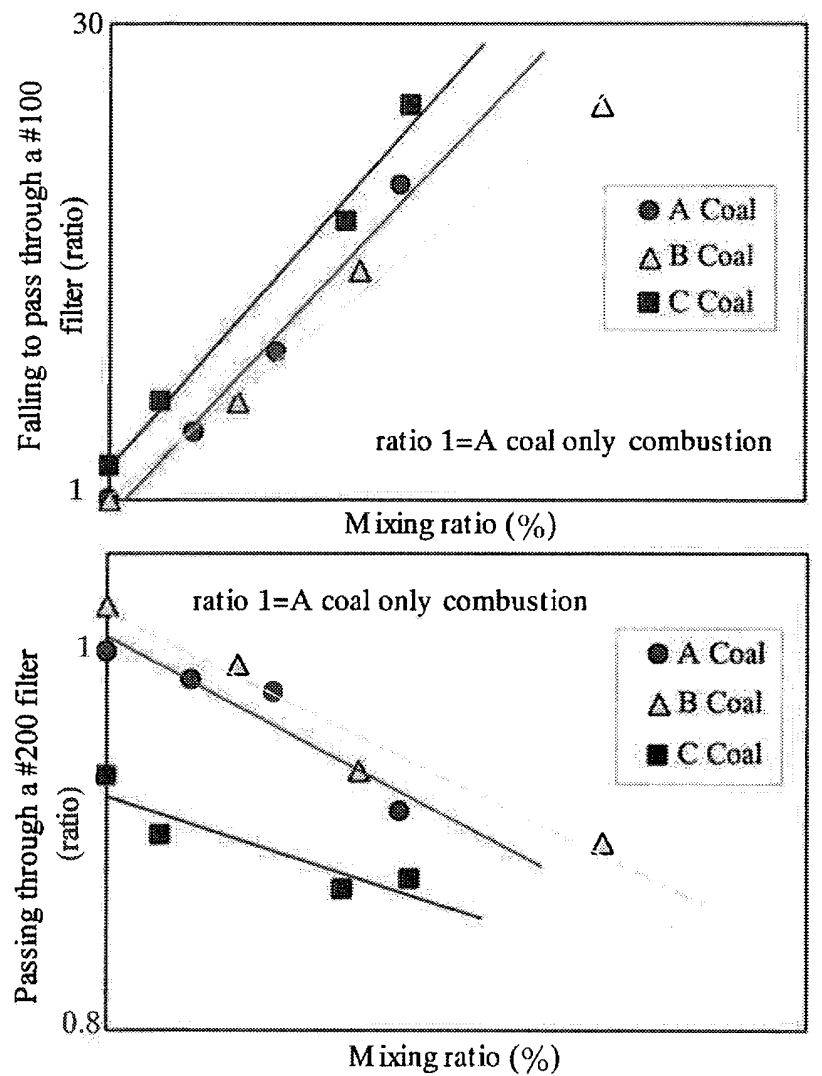

Fig. 5 Correlation between the particle size of pulverized products and mixing ratio of wood pellets 
Fig. 5 shows the correlation between the percentage of mixed fuel particles that does not pass through a \#100 mesh filter ("failing to pass through a 100 filter")/the percentage of mixed fuel particles that passes through a \#200 mesh filter ("passing through a \#200 filter") and the mixing ratio. Particles "failing to pass through a \#100 filter" grew with the increase in the mixing ratio, while particles "passing through a $\$ 200$ filter" decreased. We confirmed that pulverized particle size of the mixed fuel grow with the increase in the mixing ratio of wood pellets. Meanwhile, we confirmed that particle diameter targets can be achieved within the scope of automatic control, as long as the coal pulverizer's power consumption does not exceed the upper limit. The above-mentioned results revealed that power consumption for pulverization poses a constraint in pulverization of coal mixed with wood pellets. The coal pulverizer's power consumption for pulverization grows linearly with the increase in the mixing ratio. Thus, we were able to confirm that simple predictions as for maximum ratio of wood pellets mixing with coal can be made for different brands of coal based on the coal pulverizer's power consumption.

\section{COMBUSTION TEST}

\subsection{Experimental}

Compared with coal, wood biomass has lower nitrogen and sulfur content. Use of wood pellets (a type of wood biomass) as an alternative fuel for coal is expected to reduce nitrogen oxides and sulfur oxides in the combustion exhaust gas. Also, wood biomass is high in volatile components, and is therefore considered to offer better combustion characteristics than coal. We used wood pellets in the coal-fired boiler, and checked the four points below.

1. Automatic follow-up performance of boiler control against load changes

2 . Changes in the heat absorption balance through monitoring of temperatures at different points in the furnace and sprayed water volume

3. Emissions concentrations of nitrogen oxides/sulfur oxides

4. Unburned content in EP fly ash

\subsection{Result and Discussion}

As we evaluated the automatic follow-up performance of the control system (in terms of boiler's fuel/air water control, steam temperatures and pressure) against changes in load demand, we confirmed that the boiler control successfully achieves automatic follow-up without deviation from the boiler's control parameters, with control variations kept within tolerance. Fig. 6 shows the results of comparison in coal-only combustion and co-combustion for boiler steam temperatures, sprayed water volume, and superheater's/reheater's metal temperatures at the rated load. Because wood pellets are considered to offer better combustion characteristics than coal, we expected that ignitability might be improved by mixing wood pellets with coal, which might in turn cause changes in heat absorption balance due to changes in flame temperatures. Contrary to our expectations, demonstrable differences were not confirmed between coal-only combustion and co-combustion in terms of steam/superheater temperatures, etc. and sprayed water volume for controlling the temperatures of superheated steam. Thus, changes were not observed in the heat absorption status.
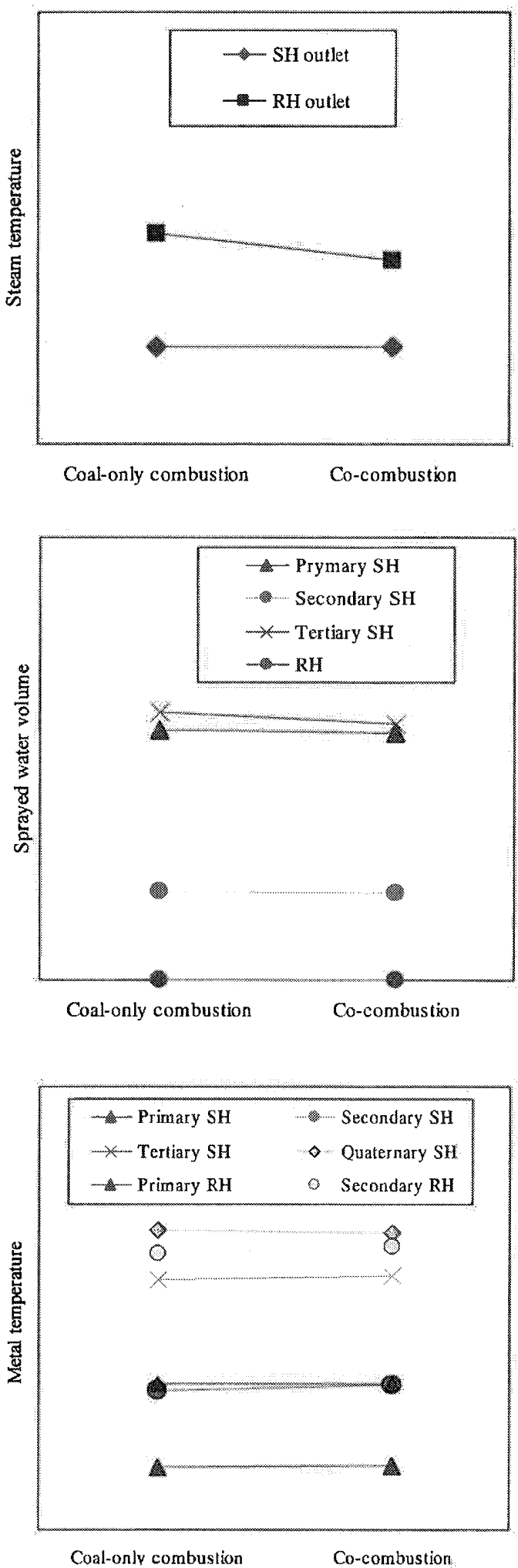

Fig. 6 Changes in Boiler Heat Absorption Balance During Coal-Only Combustion and Co-combustion.

Fig. 7 shows the concentration of nitrogen oxides and sulfur oxides in the exhaust gas during coal-only combustion and co-combustion. We expected to see lower emissions 
concentrations of nitrogen oxides and sulfur oxides in co-combustion with wood pellets. However, the results showed emissions concentrations equivalent to, or slightly lower than, those in coal-only combustion. We believe that phenomena peculiar to co-combustion of wood pellets were not confirmed in those characteristics because the mixing ratios were low.

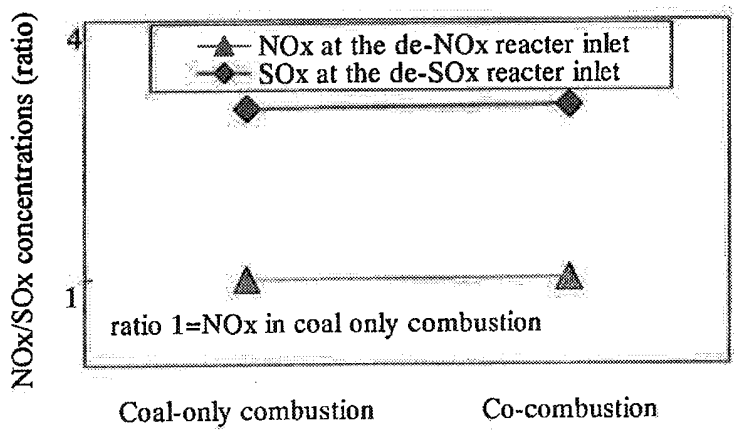

Fig. 7 Emissions Concentrations of Nitrogen Oxides and Sulfur Oxides

Fig. 8 shows the unburned content in fly ash at different mixing ratios. In the pulverization tests, we found that the particle size tends to grow large when the mixing ratio increases. For this reason, we were concerned about a potential increase in unburned content in fly ash. However, measurement results satisfied target values, and thus we confirmed that higher mixing ratios do not pose problems.

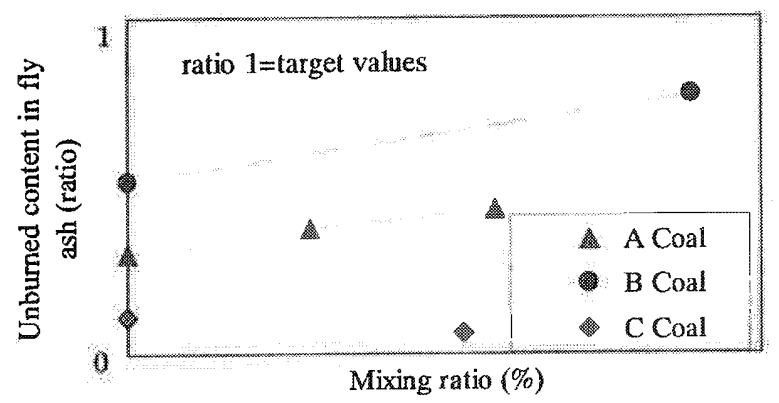

Fig. 8 Unburned Content in Fly Ash

\section{CONCLUSION}

Wood pellets were mixed with three brands of coal with different pulverization characteristics, and pulverization tests were conducted at the Plant. As a result, we confirmed that the volume of wood pellets which can be pulverized with the available capacity of the coal pulverizer (in terms of power consumption) can be estimated easily. Based on the estimated volume, we mixed wood pellets in the fuel, which was used for combustion in the boiler at the Plant. We confirmed that the combustion characteristics as well as automatic follow-up performance and heat absorption balance of the boiler are basically the same as those in coal-only combustion, thus no problem arises in combustion. 